\title{
Obesity reduces left ventricular strains, torsion and synchrony in mouse models: a cine DENSE MRI study
}

\author{
Sage P Kramer ${ }^{1 *}$, David Powell ${ }^{2}$, Cassi Binkley ${ }^{1}$, Lisa Cassis ${ }^{3}$, Frederick H Epstein ${ }^{4}$, Brandon K Fornwalt ${ }^{1,2}$ \\ From 16th Annual SCMR Scientific Sessions \\ San Francisco, CA, USA. 31 January - 3 February 2013
}

\section{Background}

Obesity is an epidemic affecting over 1 in 3 adults in the United States. Patients who are obese have increased cardiovascular mortality compared to those with normal weight, partly due to direct effects on the heart. However, the effect of obesity on advanced measures of cardiac function such as strain, torsion and synchrony are poorly understood.

\section{Methods}

Ten 12-week-old male C57BL/6 mice were randomized to one of two diets: 1) a high-fat 'western' diet with $60 \%$ of calories from fat or 2) a low-fat diet with $10 \%$ of calories from fat. After 5 months on the diet, the mice were imaged on a 7T ClinScan MRI (Bruker, Ettlingen, Germany) using a cine DENSE protocol and a 4-element phased array cardiac coil. Three short-axis slices (basal, mid, apical) and two long-axis slices (4-chamber and 2chamber) were acquired with 15-20 frames per cardiac cycle. These data were then used to quantify left ventricular strain, torsion and measures of synchrony using semi-automated post-processing software written in MATLAB (Mathworks, Natick, MA).

\section{Results}

Left ventricular sub-epicardial strain was significantly lower in the obese mice with a $40 \%$ reduction in circumferential strain $(\mathrm{p}<0.001)$, a $19 \%$ reduction in longitudinal strain $(\mathrm{p}=0.03)$, and a $53 \%$ reduction in radial strain ( $\mathrm{p}=0.06)$. By contrast, left ventricular sub-endocardial strain was modestly reduced in the obese mice in the circumferential direction by $12 \%(\mathrm{p}=0.01)$, and not

${ }^{1}$ Pediatrics, Cardiology, and Physiology, University of Kentucky College of Medicine, Lexington, KY, USA

Full list of author information is available at the end of the article significantly different in the radial $(\mathrm{p}=0.63)$ or longitudinal $(\mathrm{p}=0.44)$ directions. Peak left ventricular torsion was reduced by $34 \%$ in the obese mice $(p=0.06)$. Finally, the radial uniformity of strain index showed a reduction in the synchrony of contraction in the left ventricle $(\mathrm{p}=0.01)$ with a time delay in the septal to free wall direction.

\section{Conclusions}

Diet-induced obesity leads to a reduction in cardiac contractility in mouse models as evidenced by reductions in left ventricular strains and torsion. Reductions in cardiac strain are mostly limited to the sub-epicardial layer of the left ventricle, with relative preservation of function

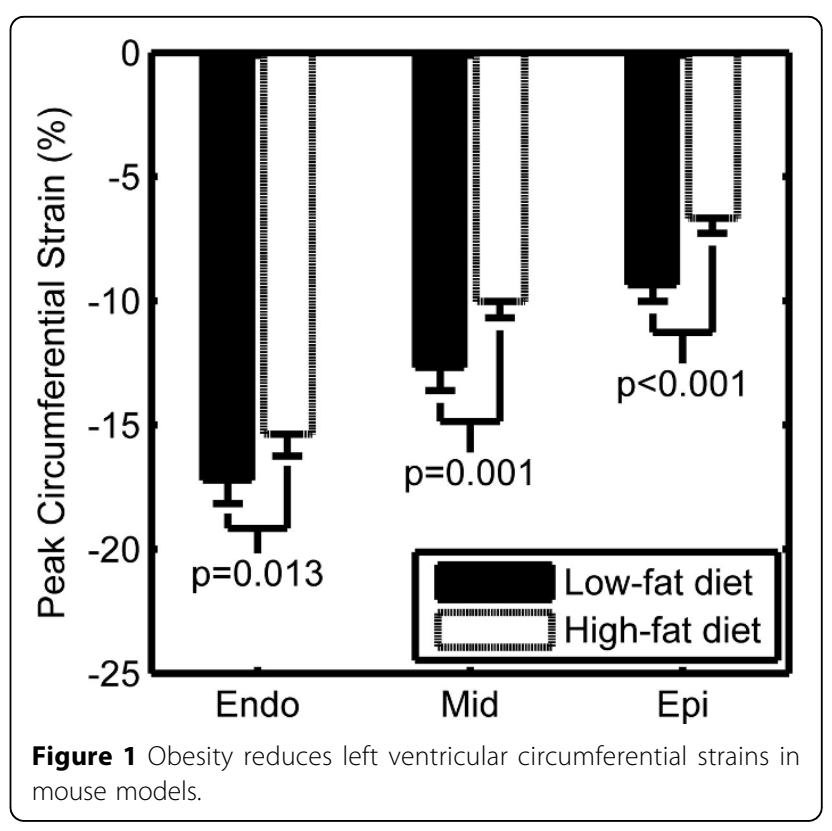


Table 1

\begin{tabular}{cccc}
\hline & Region & $\begin{array}{c}\text { Change due to } \\
\text { high-fat diet }\end{array}$ & $p$ \\
\hline Radial Strain (\%) & Endo & $+5 \%$ & 0.63 \\
\cline { 2 - 4 } & Epi & $-53 \%$ & 0.06 \\
\hline Circumferential Strain (\%) & Endo & $-12 \%$ & 0.01 \\
\cline { 2 - 4 } & Epi & $-40 \%$ & $<0.001$ \\
\hline Longitudinal Strain (\%) & Endo & $-6 \%$ & 0.44 \\
\cline { 2 - 4 } & Epi & $-19 \%$ & 0.03 \\
\hline Radial Uniformity of Strain & Average & $-5 \%$ & 0.01 \\
\hline Peak Torsion $(\% / m m)$ & Total & $-34 \%$ & 0.06 \\
\hline
\end{tabular}

in the sub-endocardium. Diet-induced obesity also leads to reduced synchrony of contraction in the left ventricle of the heart.

\section{Funding}

This work was supported by an NIH pilot project from a COBRE grant (5P20RR021954-05 and 8P20GM103527-05), the University of Kentucky Cardiovascular Research Center, and contributions made by local businesses and individuals through a partnership between Kentucky Children's Hospital and Children's Miracle network.

\section{Author details}

${ }^{1}$ Pediatrics, Cardiology, and Physiology, University of Kentucky College of Medicine, Lexington, KY, USA. ${ }^{2}$ Center for Biomedical Engineering, University of Kentucky, Lexington, KY, USA. ${ }^{3}$ Graduate Center for Nutritional Sciences, University of Kentucky College of Medicine, Lexington, KY, USA. ${ }^{4}$ Biomedical Engineering, University of Virginia, Charlottesville, VA, USA.

Published: 30 January 2013

doi:10.1186/1532-429X-15-S1-P155

Cite this article as: Kramer et al:: Obesity reduces left ventricular strains, torsion and synchrony in mouse models: a cine DENSE MRI study. Journal of Cardiovascular Magnetic Resonance 2013 15(Suppl 1):P155.
Submit your next manuscript to BioMed Central and take full advantage of:

- Convenient online submission

- Thorough peer review

- No space constraints or color figure charges

- Immediate publication on acceptance

- Inclusion in PubMed, CAS, Scopus and Google Scholar

- Research which is freely available for redistribution

Submit your manuscript at www.biomedcentral.com/submit
C Biomed Central 